\title{
ATIVIDADES AGROPASTORIS DE ABASTECIMENTO E CRISE DA MINERAÇÃO NO SÉCULO XVIII MINEIRO: SÃO JOÃO DEL-REI, 1750-1800
}

\author{
SUPPLYING BASED AGROPASTORAL ACTIVITIES AND THE \\ MINING CRISIS OF THE 18TH CENTURY IN MINAS GERAIS: SÃO \\ JOÃO DEL-REI, 1750-1800
}

DOI: http//dx.doi.org/10.15448/2178-3748.2016.2.21688

\author{
Felipe Moreira Alves de Lima \\ Mestrando - UFSJ \\ E-mail: filipe.lima@ifmg.edu.br
}

\begin{abstract}
RESUMO: O presente artigo busca apresentar alguns resultados de estudos realizados sobre a formação da elite econômica mineira estabelecida na Comarca do Rio das Mortes entre os anos de 1750-1800, espaço temporal compreendido entre a sedimentação da sociedade advinda da crise do extrativismo aurífero e a sua acomodação evolutiva para uma economia de abastecimento, fruto da consolidação das atividades agropastoris na Capitania de Minas Gerais. Dessa maneira, consideram-se as mudanças possíveis nesse processo histórico de formação das elites econômicas locais, passando de fortunas de feições derivadas do extrativismo aurífero para as de feições mercantis e principalmente agrárias. Para uma análise dos perfis da riqueza dos membros da elite são-joanense, buscou-se reconstruir a trajetória pessoal de seus elementos a partir de inventários post-mortem, selecionados através do valor de seu monte-mor. A partir da análise dos inventários examinou-se a composição e o perfil dessas fortunas, a fim de proporcionar uma melhor compreensão da dinâmica econômica da Comarca do Rio das Mortes e da capitania mineira na segunda metade dos setecentos.
\end{abstract}

PALAVRAS-CHAVE: História econômica de Minas Gerais. Elite econômica. Atividades agropastoris

ABSTRACT: This article aims at presenting partial results of the study I conducted on the formation of the economic elite in Minas Gerais established at Comarca do Rio das Mortes between 1750 and 1800 . This time periodencompasses the consolidation of the society that emerged from the crisis of gold exploitation and its evolutionary accommodation towards a supplying based economy, a consequence of the consolidation of agropastoral activities at Capitania de Minas Gerais. Therefore, this article considers possible changes on the historical processes in the formation of local economic elites, which go from fortunes with characteristics of the gold exploitation to the ones with mercantile characteristics, mainly agricultural. In order to analyze the fortune profiles of the members of São João Del-Rey elite, I aimed at reconstructing the personal trajectory of its participants from post-mortem inventories selected based on the value of its totality of goods for inheritance. Through the analysis of the inventories, the composition and the profile of such fortunes were analyzed in order to enable a better understanding of Comarca do Rio das Mortesand Capitania Minas Gerais'economic dynamics in the second half of the $18^{\text {th }}$ Century.

KEYWORDS: Economic history of Minas Gerais. Economic elite. Agropastoral activities.

A COMARCA DO RIO DAS MORTES E A HISTORIOGRAFIA SOBRE AS MINAS COLONIAL 
Em pesquisas recentes tivemos a oportunidade de estudar alguns aspectos da elite econômica estabelecida na Vila de São João, Comarca do Rio das Mortes, durante a segunda metade do século XVIII. Em tais estudos pudemos, através dos inventários post-mortem, analisar o perfil e a composição das maiores fortunas de São João del-Rei entre os anos de 1750 a 1800, o que demonstrou a necessidade de um olhar mais atento sobre as atividades agropastoris desenvolvidas na Comarca do Rio das Mortes. Os resultados obtidos apontavam para uma presença significativa de fortunas que tinham origem nas atividades agropastoris, indicando a necessidade de um estudo mais aprofundado, que tivesse o desenvolvimento dessa atividade, bem como a relação com enriquecimento daqueles que a praticavam, como foco.

Os resultados que pretendemos discutir ao longo do presente trabalho corroboram com diversos estudos sobre a capitania de Minas Gerais ${ }^{1}$, que têm demonstrado que, mesmo no período de auge da exploração aurífera, diversas atividades econômicas, como as agropastoris, já estavam presentes de maneira significativa no conjunto da economia mineira, demonstrando também que essas atividades não se desenvolveram apenas em um contexto de declínio da exploração aurífera, e nem tampouco, se restringiam a uma simples agricultura de subsistência, como sugere parte da historiografia que se dedica a estudar a economia colonial mineira ${ }^{2}$.

Fundamental nesse sentido é o artigo de autoria de Guimarães e Reis (1986), em que os autores chamam a atenção para a coexistência das atividades agropastoris com a mineração desde o período de auge desta última atividade. Os autores destacam ainda o caráter escravista das atividades agropastoris desenvolvidas na capitania desde a primeira metade dos setecentos, refutando a ideia de que atividades distintas da mineração não tinham a capacidade de adquirir grandes plantéis escravistas ${ }^{3}$, demonstrando assim o dinamismo dessas atividades.

\footnotetext{
${ }^{1}$ São exemplos de trabalhos que abordam o tema José Newton Coelho Meneses (2000; 2007) e Flávio Marcus da Silva (2007).

${ }^{2}$ É possível exemplificar essa interpretação a partir das obras de Celso Furtado (1977) e Roberto Simonsen (1979). Celso Furtado (1977) compreende que durante o "ciclo da mineração" não se formou em Minas nenhuma outra forma de atividade econômica permanente, com a exceção de uma agricultura de subsistência, de impacto quase irrelevante no conjunto da economia. Desse modo, quando as atividades de exploração mineral declinam, declina toda a economia mineira, que logo se torna decadente. Já Simonsen (1979), de um modo geral, não difere muito de Furtado (1977) em relação às demais atividades econômicas praticadas nos setecentos mineiro. Para o autor, assim como em Furtado (1977), o declínio das atividades de exploração aurífera teria colocado toda a região centro-sul em decadência, uma vez que apenas os produtos exportáveis gerariam lucros significativos.

${ }^{3}$ Concorda-se com Francisco Carlos Teixeira (1990), quando o autor afirma que o efeito negativo das atividades auríferas sobre a agricultura, algo muito abordado pela historiografia brasileira, deve ser visto com cuidado. Pois,
} 
Assim como Guimarães e Reis (1986), Laird Bergad (2004) também destaca a importância das atividades agropastoris no conjunto da economia mineira setecentista. De acordo com o autor, o mercado de gêneros alimentícios permitia grandes lucros, ao ponto de possibilitar que, já no início do século XVIII, fazendas com produções diversificadas se estabelecessem em Minas Gerais. Sobre o século XVIII, afirma Bergad que "não há nenhuma dúvida de que nesse período a comercialização agrícola estivesse bastante disseminada em Minas”. (BERGAD, 2004, p. 58)

Ainda sobre a disseminação da comercialização de produtos agrícolas na Capitania, Alexandre Mendes Cunha (2007), tem oferecido importantes contribuições para a historiografia sobre as minas setecentistas ao analisar a origem dos núcleos populacionais da capitania de Minas Gerais. Descrevendo as relações entre o urbano e o rural, o autor afirma que durante o século XVIII a base urbana criada pela exploração mineral foi responsável pela constituição de um espaço rural, devido à necessidade que esses centros tinham de "fluxo regular de abastecimento". Ou seja, se por um lado a mineração forjou a criação das primeiras vilas da capitania de Minas Gerais, como ocorreu com a própria Vila de São João del Rei, principal vila da Comarca do Rio das Mortes, o mercado constituído por esses centros urbanos estimularam a produção de gêneros alimentícios em um espaço rural, integrado pela comercialização de gêneros alimentícios aos centros urbanos.

Já Raphael Freitas Santos (2010), ao analisar a Comarca do Rio das Velhas, situada mais ao norte da Capitania de Minas Gerais, nos fornece contribuições para uma melhor compreensão das atividades agropastoris desenvolvidas na capitania ao longo dos setecentos, bem como a sua relação com o enriquecimento de quem as praticavam. Em um breve estudo o autor demonstra que a produção rural voltada para o mercado interno configurava-se como uma das atividades mais lucrativas e dinâmicas daquela região durante o século XVIII. Analisando os anos de 1713 a 1773, Santos (2010) aponta que as atividades agropastoris já eram uma importante alternativa à mineração no que tange a atuação dos homens mais abastados da comarca do Rio das Velhas, mesmo em um momento de auge da exploração mineral. $\mathrm{O}$ fato das atividades agropastoris se constituírem como uma alternativa à mineração no que tange a atuação dos membros da elite econômica local, como bem identificou Freitas Santos para a Comarca do Rio das Velhas, foi também verificado para a Comarca do Rio das Mortes, como veremos adiante.

se por um lado houve uma inflação no preço dos escravos, por outro, a exploração do ouro criou também um mercado interno com níveis de remuneração mais elevados. 
Contudo, apesar da importância dos estudos anteriormente destacados, percebe-se que, se tratando especificamente da Comarca do Rio das Mortes, ainda são escassos os trabalhos que se dedicam às atividades agropastoris desenvolvidas na Comarca ao longo do século XVIII, sendo mais conhecida a importância dessas atividades no alvorecer e decorrer do século XIX. Como exemplo de trabalhos que analisam a economia são-joanense no século XIX, é possível destacar as contribuições de Afonso de Alencastro Graça Filho (2002; 2013). De acordo com o autor "a Comarca do Rio das Mortes destacou-se como área abastecedora de alimentos para a Província do Rio de Janeiro desde as primeiras décadas dos séculos XIX, antes do início da montagem da cafeicultura fluminense" (GRAÇA FILHO, 2002, p. 36). Tais apontamentos corroboram com a necessidade de melhor compreender o que ocorre entre os séculos XVIII e XIX que permite que, já no alvorecer do século XIX, a Comarca do Rio das Mortes se destacasse como um importante centro abastecedor de gêneros alimentícios.

O crescimento econômico da Comarca do Rio das Mortes no início do século XIX já havia sido registrado nos diários e apontamentos de alguns viajantes que conheceram essa região de Minas Gerais no exato momento em que o processo de "acomodação evolutiva"4 estava em curso, como é o caso do viajante-naturalista Auguste de Saint-Hilaire, que esteve nas Minas Gerais nos anos de 1816 e 1822.

De acordo com Saint-Hilaire, a região de Vila Rica, atual cidade de Ouro Preto, que "floresceu enquanto os terrenos que a rodeiam forneciam ouro em abundância; à medida, porém, que o metal se foi tornando raro ou de extração mais difícil, os habitantes foram pouco a pouco tentar fortuna em outros lugares, e, em algumas ruas, as casas estão quase abandonadas". (SAINT-HILAIRE, 1938a, p.130)

Já as descrições do mesmo viajante referentes à região da Comarca do Rio das Mortes atestam um cenário distinto, indicando maior vitalidade econômica, o que se exemplifica em suas descrições sobre as moradias e plantações de tal região. Diz Saint-Hilaire: "os proprietários abastados têm plantações a alguma distância, em melhores terrenos, e criam animais em pastos excelentes que fazem a riqueza deste distrito" (SAINT-HILAIRE, 1938b, p.84). Passando por onde hoje é a cidade de Barbacena, cidade vizinha a São João del-Rei, o viajante francês, analisando as plantações, observa que "por todos os lados veem-se campos de milho entremeados de pastos e moitas de arvoredo" (SAINT-HILAIRE, 1938a, p.112)

\footnotetext{
${ }^{4}$ A fase de acomodação evolutiva da economia mineira, que ocorre após o auge minerador, pode ser entendido como um momento em que a economia da capitania de Minas Gerais passa por um momento de diversificação de sua produção, com uma tendência a alcançar a autossuficiência (ALMEIDA, 2010). Na Comarca do Rio das Mortes esse período é marcado pela consolidação das atividades agropastoris de abastecimento.
} 
$\mathrm{Na}$ historiografia que trata sobre o assunto, Kenneth Maxwell (2005) aponta importantes transformações que ocorreram na capitania nesse período e que de alguma forma corroboram com as observações de Saint-Hilaire. Como exemplo, Maxwell destaca a Comarca de Vila Rica, que nas quatro décadas posteriores ao censo realizado em 1776 apresentou uma queda populacional significativa, enquanto a Comarca do Rio das Mortes quase triplica sua população, que salta de 82.781 habitantes no ano do censo, para $213.617 \mathrm{em}$ 1821. Para Maxwell esse rearranjo populacional é entendido como fruto do declínio da mineração e da ascensão das atividades agropastoris na Comarca do Rio das Mortes.

A "vocação agrícola" da comarca do Rio das Mortes, como define Zemella (1990), presente desde os primórdios da ocupação dessa região, não raras vezes é citada em trabalhos sobre a economia mineira, como bem aponta Graça Filho (2002). Porém, persiste a necessidade de estudos empíricos capazes de proporcionar uma melhor compreensão das características dessa atividade durante a segunda metade do século XVIII e início do século XIX, a fim de melhor compreender qual o real impacto do declínio da mineração sobre as atividades agropastoris de abastecimento e sobre a comarca do Rio das Mortes, e como esse impacto é sentido pela economia local na passagem do século XVIII para o século XIX.

Estudos recentes, como os de Carlos de Oliveira Malaquias (2010), tem demonstrado que durante o século XVIII a exploração do ouro em São José del-Rei, atual cidade de Tiradentes, vila vizinha a São João del Rei, concentrou-se, principalmente, na vila propriamente dita, sendo a busca pelo metal precioso algo raro ou mesmo inexistente nos demais distritos, que "por sua vez, especializaram-se no agropastoreio - opção viável e lógica dados a disponibilidade e qualidade das terras, a modéstia dos investimentos para um empreendimento pequeno e amplo mercado consumidor nas minas" (MALAQUIAS, 2010, p.3).

Portanto, se é aceita a idéia de que as atividades agropastoris desenvolvidas na Comarca do Rio das Mortes eram uma "opção viável e lógica", como define Malaquias (2010), ou uma "vocação", como define Zemella (1990), torna-se latente a necessidade de estudos empíricos que se proponham a melhor conhecerem as principais características dessa atividade econômica desenvolvida na comarca, e a sua relação com as grandes fortunas locais. Lançar algumas luzes sobre essas questões é o objeto principal desse trabalho.

Logo, ao definir o recorte temporal, de 1750 a 1800, buscamos examinar as principais características das atividades agropastoris voltadas para o abastecimento em um período que abrange o auge e declínio das atividades da mineração, segundo a periodização proposta por 
Carla Almeida $(2010)^{5}$. Os resultados aqui expostos giram em torno da identificação e da análise do perfil das riquezas oriundas das atividades agropastoris voltadas para o abastecimento desenvolvidas no Termo da Vila de São João del Rei, principal Vila da Comarca do Rio das Mortes, na segunda metade do século XVIII.

\section{OS PERFIS DAS FORTUNAS ANALISADAS: A IMPORTÂNCIA DAS ATIVIDADES AGROPASTORIS NO CONJUNTO DAS GRANDES FORTUNAS DA VILA DE SÃO JOÃO DEL REI}

Na identificação e análise dos padrões de investimentos da elite econômica local, bem como na observação das mudanças das opções de investimentos dessa elite dentro do período proposto, foram analisados inventários post-mortem, fontes consideradas privilegiadas para esse tipo de análise ${ }^{6}$. Entre todos os inventários disponíveis para a Vila de São João del Rei, entre os anos de 1750 e 1800, apenas aqueles que possuíam monte-mor ${ }^{7}$ mínimo de 10 contos de réis foram selecionados para análise dos perfis das fortunas.

O patamar de dez contos de réis foi utilizado por Mattoso (1992) como um divisor entre as médias e as maiores fortunas de Salvador para o século XIX. Já para Minas Gerais, Carlos Kelmer (2012) adota esse patamar para identificar as fortunas médias altas da Vila do Carmo, Comarca de Vila Rica, entre os anos 1713 a 1756. Ainda nesse sentido vale destacar o trabalho de Almeida (2001), que também utiliza o patamar mínimo de dez contos de réis para identificar as maiores fortunas do século XVIII mineiro.

Dessa forma, vale ressaltar que o termo "elites", que em um primeiro momento pode ser considerado polissêmico, assume aqui uma definição mais restrita, baseada em critérios econômicos, a exemplo de trabalhos citados anteriormente. Logo, tratamos como membros da

\footnotetext{
5 A periodização proposta por Almeida (2010) divide os anos compreendidos entre 1750 e 1850 em três subperíodos. De acordo com a autora, o primeiro subperíodo, que compreende os anos de 1750 a 1770 , é caracterizado pelo auge minerador, pois embora decrescente, a mineração permanecia como a atividade principal da capitania de Minas Gerais. Já entre os anos de 1780 a 1810 a mineração deixa de ser a atividade principal, lugar que é, paulatinamente, ocupado pelas atividades agrárias. Já os anos de 1820 a 1850 são marcados pela consolidação e predomínio das atividades mercantis de abastecimento. Para o recorte aqui adotado, são fundamentais os dois primeiros subperíodos, que englobam o auge minerador (1750-1770) e a transformação da economia mineira, que as poucos assume feição mais agrária (1780-1810).

${ }^{6}$ De acordo com Sheila de Castro Faria (1998), os inventários post-mortem são fontes privilegiadas para a análise da vida material do período colonial, pois a quantidade de bens listados nos inventários abrange quase a totalidade dos bens materiais que pertenciam ao sujeito na hora de sua morte.

${ }^{7} \mathrm{O}$ termo monte-mor se refere ao valor total dos inventários post-mortem, ou seja, a somatória de todos os bens descritos e avaliados durante a confecção dos documentos.
} 
elite econômica local aqueles indivíduos que, ao falecerem, possuíam valor de monte-mor de no mínimo dez contos de réis.

Se, por um lado, o termo elites assume uma feição mais restrita, baseada em critérios econômicos, por outro, compreendemos que, no período colonial, a acumulação de riqueza trazia como conseqüência o reconhecimento na hierarquia social. Nesse sentido a abordagem aqui proposta é próxima da definição de Maria Fernanda Bicalho (2005), segundo a qual o termo elites assume uma conotação econômica, porém, não se restringindo apenas à posse de extensos cabedais. Para a autora, a elite colonial brasileira, assim como a sua congênere reinol, tinha como característica a acumulação de um amplo patrimônio, ocupação de cargos administrativos e o recebimento de mercês por serviços prestados à Coroa e, mais específica da realidade colonial brasileira, a posse de escravos.

Os trabalhos de João Fragoso (2005) também são úteis na busca de uma definição mais precisa do termo elites. O conceito de nobreza da terra ou elite colonial se assenta na capacidade de mando na administração colonial, o que se relaciona com a riqueza adquirida, pois os cabedais angariados permitiam certa ingerência na condução administrativa e no mercado, através, por exemplo, da ocupação de postos na Câmara.

Para se chegar aos resultados que se seguem foram analisados 665 inventários postmortem $^{8}$, todos dentro recorte temporal de 1750 a 1800, e tendo como limitação geográfica a Vila de São João del-Rei e suas localidades que compunham o termo. Ao analisar os inventários post-mortem buscamos principalmente compreender o perfil dos bens arrolados, tentando dessa forma traçar uma breve comparação entre os diferentes perfis de riqueza, tais como riquezas advindas de atividades minerais, riquezas advindas de atividades prestamistas e aquelas oriundas de atividades agropastoris, foco dessa investigação.

Cronologicamente, os inventários encontrados que possuíam valor de monte-mor igual ou superior a dez contos de réis, critério precípuo para análise dos mesmos, se dividem da seguinte forma: para o período de 1750 a 1779, período, segundo Almeida (2010), de auge da mineração em boa parte da Capitania de Minas Gerais, encontramos 8 inventários. Já para o momento seguinte, de 1780 a 1800 , período em que a mineração deixa de ser a principal atividade, encontramos 11 inventários.

Do total dos inventários pesquisados apenas 19, ou 2,85\%, atingiam o recorte mínimo estabelecido, o que já demonstra um aspecto fundamental dessa sociedade que se sedimentou nas Minas Gerais durante o período colonial, qual seja, a concentração de riqueza. Laura de

\footnotetext{
${ }^{8}$ Arquivo Histórico de São João del-Rei/IPHAN - Inventários post-mortem .
} 
Mello e Souza (1982) já tinha demonstrado que havia em Minas Gerais no período colonial alguns homens possuidores de grandes fortunas, no entanto predominava a pobreza da maioria da população local.

Autores como Wilson Cano (1977) também perceberam esse caráter pouco democrático no que tange a distribuição da riqueza no período colonial mineiro. Contrastando com a idéia de que as possibilidades advindas da exploração mineral teriam criado em Minas Gerais uma sociedade marcada por uma maior distribuição de riqueza quando comparadas com outras sociedades, como aquelas sedimentadas em torno do cultivo da cana de açúcar, afirma o autor:

Como certamente operou a custos elevados, provavelmente suas margens de lucro eram baixas para os medianamente bem sucedidos, altas para os poucos afortunados, isto é, para aqueles de maior sorte no encontro do minério, e ínfimas, e até mesmo negativas, para muitos, para os mal sucedidos. (Cano, 1977, p.106)

O que a análise dos inventários demonstrou é que na Vila de São João del Rei o perfil de uma sociedade com poucos homens abastados e muitos homens pobres também existiu, corroborando, nesse sentido, com o que propõe Cano (1977). Ao que tudo indica a sociedade sanjoanense setecentista também era marcada pela polarização econômica, assim como outras regiões das Minas Gerais.

Mesmo entre aqueles que possuíam significativos cabedais, e, portanto, eram membros da elite econômica local, havia significativa diferença nos valores das fortunas acumuladas. É o que demonstram os valores de monte-mor, que corresponde à soma total dos bens arrolados nos inventários, encontrados durante a pesquisa. Encontramos uma média de 17:364\$552 por inventário, sendo o maior valor de 60:030\$131 ${ }^{9}$ réis. O inventário é do ano de 1763 e pertence ao português Antônio de Freitas. Já o menor valor encontrado, de acordo com mínimo estabelecido de 10 contos de réis, foi de 11:030\$880 ${ }^{10}$ e pertence à Constantino Barbosa da Cunha, que ao morrer, no ano de 1772, tinha como atividade principal a exploração aurífera, contando com lavras e terras minerais.

A fortuna acumulada por Antônio de Freitas exemplifica essa polarização social, característica das Minas Gerais no período colonial, quando comparada, por exemplo, à

\footnotetext{
${ }^{9}$ Arquivo Histórico de São João del-Rei/IPHAN - Inventários post-mortem- ano 1763, caixa 94.

${ }^{10}$ Arquivo Histórico de São João del-Rei/IPHAN - Inventários post-mortem - ano 1771, caixa 614.
} 
pequena quantia deixada por José Ferreira Duarte ${ }^{11}$. Português por nascimento e falecido na Vila de São João del Rei no ano de 1762, o inventariado em questão era Tesoureiro do Juízo da dita Vila, e muito provavelmente conhecia o também português Antônio de Freitas, que também vivia na vila São João del-Rei e faleceu apenas alguns meses depois de José Ferreira Duarte, no ano de 1763. Apesar de terem vivido na mesma vila, terem a mesma origem de nascimento e pouco tempo de diferença entre a morte de um e de outro, as diferenças nos níveis de fortunas colocavam esses homens em condições completamente distintas na hierarquização social que estava sendo estabelecida na Vila de São João del Rei.

Ao morrer José Ferreira Duarte deixou para os seus descendentes a pequena quantia de $136 \$ 680$ réis, valor que seria o mínimo necessário para a compra de um escravo jovem nas Minas Gerais do período, sendo esse um dos menores valores de monte-mor encontrado durante toda a pesquisa. Já o seu conterrâneo, Antônio de Freitas, estava situado no outro extremo dessa polarização, com uma fortuna somada em 60:030\$131, a maior fortuna encontrada.

Com uma escravaria composta por 15 escravos, 12 deles africanos, avaliados em 1:910\$000, e uma fazenda que contava com engenho de moer cana e farinha, e ainda com um valor significativo de dívidas a receber, ao falecer Antônio de Freitas possuía uma fortuna cerca de 440 vezes maior que a do tesoureiro do Juízo, José Ferreira Duarte.

Não é só em relação à concentração de riqueza que o inventário de Antônio de Freitas é emblemático, pois vale destacar ainda a pouca importância das atividades ligadas à mineração na composição de sua fortuna, que, ao que tudo indica, tinha origem principalmente nas atividades agropastoris e nas dívidas a receber, o que por sua vez, podem ser oriundas da comercialização de sua produção, já que o inventariado em questão produzia em níveis muito superiores ao da subsistência.

Nesse sentido, o inventário de Antônio de Freitas não surge como uma exceção, pois ao analisar as atividades econômicas desempenhadas pelos membros dessa elite, encontramos oito inventários em que os inventariados tinham suas riquezas oriundas de atividades agropastoris e três em que as riquezas eram oriundas de atividades ligadas ao comércio ou a atividades prestamistas. Já para a mineração, identificamos apenas três documentos com riquezas originadas na exploração aurífera. Em cinco inventários previamente selecionados, não foi possível identificar com precisão o perfil das fortunas arroladas, em decorrência do estado deteriorado que se encontram estes documentos.

\footnotetext{
${ }^{11}$ Arquivo Histórico de São João del-Rei/IPHAN - Inventários post-mortem - ano 1762, caixa 345.
} 
Os números expostos acima, e principalmente os perfis das riquezas encontradas, demonstram a importância das atividades agropastoris na composição das riquezas desses homens, o que corrobora com os vários estudos citados ao longo deste trabalho. Porém, o fato de terem sido identificados poucos inventários relacionados à mineração deve ser relativizado, pois a maior parte dos inventários analisados é das décadas de 1780 e 1790, e refletem um momento de decadência da exploração aurífera e fortalecimento das atividades agropastoris, transformações inseridas em um contexto de uma economia que se tornava cada vez mais diversificada.

Os resultados da análise do padrão da posse de escravos por inventário também corroboram com esse contexto econômico, marcado principalmente pela consolidação das atividades agropastoris. Para essa atividade encontramos uma média de 54,4 escravos por inventário, o que, por sua vez, demonstra a importância da mão-de-obra escrava nas atividades agropastoris de abastecimento. Como indica Bergad (2004), o uso da mão-de-obra escrava na agricultura desenvolvida nas Minas setecentistas é de fundamental importância quando o que se busca é uma produção de alimentos que supere a subsistência e alcance a venda da produção em mercados, pois "o nível de produção é determinado pelo número de braços que trabalham a terra" (BERGAD, 2004, p. 57), haja vista a pouca tecnologia disponível para o desenvolvimento dessas atividades.

O exemplo de Thomás Dias Mota ${ }^{12}$, falecido no ano 1767 na Vila de São João del-Rei, facilita a compreensão do que afirma Bergard (2004). No momento da sua morte o inventariado possuía uma fortuna estimada em 12:509\$179, sendo que boa parte dessa fortuna estava distribuída entre os escravos que possuía e a sua fazenda. Chamada de Engenho do Caminho Novo do Campo, sua fazenda, avaliada em 6:400\$000, valor elevado quando comparado às demais fazendas encontradas, contava com engenhos de açúcar e de farinha, além de plantações de milho e de feijão, gêneros básicos que compunham o cotidiano alimentar mineiro (MENESES, 2007). Toda essa fazenda contava com a mão-de-obra de 59 escravos, a maioria do sexo masculino (apenas 15 eram do sexo feminino), que permitia que essa produção ultrapassasse os níveis de subsistência e fosse comercializada. Outro indício da comercialização dessa produção é o fato de Thomás Dias Mota possuir 29 bestas, avaliadas em 1:207\$000. Esses animais de carga eram fundamentais para o transporte dos gêneros alimentícios consumidos nas Minas Gerais, pois o transporte no lombo de animais, como as bestas, se constituía como um dos únicos meios pelos quais os alimentos poderiam chegar a

${ }^{12}$ Arquivo Histórico de São João del-Rei/IPHAN - Inventários post-mortem - ano 1767, caixa 534. 
algumas regiões mineiras, marcadas pelo relevo montanhoso e extremamente acidentado, impossível de ser vencido pelos carros-de-boi. Podemos afirmar que o tamanho da escravaria que Thomás Dias Mota possuía era uma condição necessária para se alcançar um nível de comercialização da produção de gêneros alimentícios, o que, por sua vez, foi capaz de propiciar ao inventariado o acúmulo de tamanha riqueza.

As características e os perfis das riquezas encontradas nos inventários que tinham suas fortunas oriundas no desenvolvimento de atividades agropastoris também podem ser melhor compreendidas a partir da análise do inventário post-mortem de Emerenciana Elena de Santana ${ }^{13}$, falecida no ano de 1796 na sua fazenda chamada Engenho da Ponte, situada na Aplicação da Capela da Conceição da Barra, Termo da Vila de São João del-Rei. Os bens de raiz e as plantações que podem ser observados no dito inventário merecem destaque pela diversidade de atividades econômicas desenvolvidas pela inventariada. A fazenda chamada Engenho da Ponte era composta por casas de vivenda, engenho de cana, senzalas, paiol, chiqueiro, moinho de cana-de-açúcar, casa de tenda de ferreiro, quarto de hóspedes, casa de tropa, forno de telha, terras de cultivo, matos virgens e capoeiras, tudo isso avaliado na quantia de 2:940\$000 réis.

Emerenciana Elena de Santana tinha ainda sob sua propriedade dois canaviais para moer, que totalizavam 1:400\$000 réis, além de milho estocado no paiol da fazenda, na quantidade de 20 carros, totalizando $36 \$ 000$ réis, e ainda feijão plantado, na quantidade de $30 \$ 000$ réis. Encontramos ainda na descrição de seus bens um alambique, cujo valor não pôde ser identificado. Já a sua escravaria era composta por 35 cativos, que, em sua maioria, eram escravos do sexo masculino, de origem africana e em idade produtiva, avaliados em um total de 3:800\$000 réis, o que dá um valor médio de 108\$571 réis por escravo.

Os bens arrolados e presentes no documento em questão fornecem indícios de uma possível comercialização dessa produção, além da possibilidade de ser essa fazenda um local onde as tropas viajantes, responsáveis pelo abastecimento alimentar das Minas setecentistas, poderiam pernoitar antes de seguir viagem. Corrobora com essa ideia a presença de quartos de hóspedes e casa de tropa descritas em seus bens de raiz, e em relação à comercialização de sua produção, a presença de 4 escravos identificados como "escravos de tropa" e de 18 "bestas da tropa", avaliadas em 409\$000 réis, podem ser indícios do transporte dessa produção para comercialização da mesma.

${ }^{13}$ Arquivo Histórico de São João del-Rei/IPHAN - Inventários post-mortem - ano 1796, caixa 588. 
Foram identificados na produção de alimentos produtos como milho, feijão, açúcar e aguardente, sendo de maior vulto os dois últimos, o que permite classificar Emerenciana Elena de Santana como uma produtora de açúcar e aguardente. Como dito anteriormente, produtos como feijão e milho e o cultivo da cana-de-açúcar, com a qual se produzia aguardente, rapadura e açúcar, compunham os principais produtos consumidos pelos mineiros do período analisado, como nos aponta José Newton Coelho Meneses (2007). De acordo com o autor

esses produtos - milho, feijão, mandioca e arroz - eram os alimentos cotidianos plantados pela maioria dos lavradores. Além deles, cultivava-se a cana-de-açúcar, da qual se produzia a aguardente, a rapadura e algum açúcar, produtos que adoçavam o espírito, os alimentos e as bebidas (MENESES, 2007, p.347).

A produção desses gêneros e a sua possível comercialização permitiram que, ao fim de sua vida, a inventariada atingisse a quantia de 12:381\$500 réis, sendo considerada, a partir do recorte proposto, uma das pessoas mais abastadas da Vila de São João del-Rei na segunda metade do século XVIII.

Já nos inventários em que a riqueza era advinda das atividades de mineração, a média de escravos encontrada foi de 52 escravos por inventário, o que demonstra que, apesar de estarem em declínio, as atividades ligadas ao extrativismo mineral ainda permitiam àqueles mais auspiciosos níveis consideráveis de fortuna.

A análise das atividades prestamistas revelou uma média de 13,67 escravos por inventário, o que é condizente com a natureza dessa atividade. Embora o número médio de escravos seja menor que nas outras atividades econômicas, é necessário ressaltar que esse menor número não caracteriza um padrão de riqueza inferior. O que pode ser observado nos três inventários que foram enquadrados nessa categoria é que há, nas atividades prestamistas, características diversas de investimento em relação às demais atividades econômicas analisadas.

É o que demonstra o inventário post-mortem de Antonio Moreira Ribeiro ${ }^{14}$, falecido em 1786 na Vila de São João del-Rei. Antonio Moreira Ribeiro, ao falecer, teve seus bens inventariados pela sua viúva, Juliana de Souza Soares, que contabilizou a quantia de 21:534\$740 réis, sendo grande parte dessa fortuna advinda das atividades prestamistas. Entre

${ }^{14}$ Arquivo Histórico de São João del-Rei/IPHAN - Inventários post-mortem - ano 1786, caixa 213. 
os bens arrolados do inventariado identificamos indícios de produção de gêneros alimentícios, o que pode ser exemplificado pela posse de uma fazenda localizada na aplicação de São Gonçalo, que conta com senzala coberta de telha, casa de carro, dois moinhos e uma escravaria composta por 34 cativos. Porém, o fato de Antonio Moreira Ribeiro possuir um valor significativo de dívidas ativas, um total de 14:654\$309 réis dividido entre 83 pessoas, o que corresponde a cerca de $68 \%$ do seu monte-mor, nos permite classificá-lo como prestamista.

De um modo geral, a preponderância de dívidas ativas, como as encontradas no inventário acima mencionado, além de outras características, é o que permite enquadrar três inventários na categoria de atividades prestamistas. Além do inventário já citado, temos nessa categoria os inventários de Antônio de Freitas ${ }^{15}$, falecido no ano de 1763, e Maria Teresa de Jesus ${ }^{16}$, falecida em 1794.

Por último, na categoria de comerciante, foi encontrado um único inventário, o de Agostinho Ferreira da $\operatorname{Costa}^{17}$, que possuía um monte-mor de 12:242\$660. Agostinho Ferreira tinha apenas 5 escravos, sendo que um era considerado velho e doente, e por isso sem valor. De todos os inventários pesquisados, esse é o menor número de escravos encontrado, o que não deixa de ser condizente com a principal atividade econômica desenvolvida pelo inventariado. Entre os bens arrolados no inventário de Agostinho Ferreira da Costa, merecem destaque as dívidas ativas, que contabilizavam um total de 5:790\$686, ou seja, 47,3\% do total de seu monte-mor. Já as dívidas passivas descritas atingiam a quantia de 2:033\$639 e são fruto de entradas de mercadorias, como cargas de secos e molhados, registradas no Caminho Novo, mais um indício das práticas comerciais desenvolvidas pelo inventariado em questão.

\section{DIVERSIFICAÇÃO ECONÔMICA E CRISE DA MINERAÇÃO}

No decorrer deste trabalho buscamos demonstrar, a partir da historiografia sobre o tema e da pesquisa com os inventários post-mortem, que embora seja inegável a importância da mineração para a capitania de Minas Gerais, essa atividade se desdobrou e se diversificou na segunda metade do século XVIII. A exploração da mineração trouxe estímulos para o crescimento da agricultura de gêneros alimentícios, como aqueles produzidos na Fazenda

\footnotetext{
${ }^{15}$ Arquivo Histórico de São João del-Rei/IPHAN - Inventários post-mortem - ano 1763, caixa 94.

${ }^{16}$ Arquivo Histórico de São João del-Rei/IPHAN - Inventários post-mortem - ano 1794, caixa 124.

${ }^{17}$ Arquivo Histórico de São João del-Rei/IPHAN - Inventários post-mortem - ano 1791, caixa 66.
} 
chamada Engenho da Ponte, propriedade de Emerenciana Elena de Santana ${ }^{18}$. Com o crescimento e diversificação das atividades de agropecuária e de outras atividades, como as prestamistas ou o comércio, novas opções de atuação dos membros da elite econômica local se efetivaram ao lado da mineração, muito embora fosse comum o exercício simultâneo de mais de uma dessas atividades.

A partir dos dados encontrados nos inventários consultados e também na bibliografia que guiou a pesquisa, podemos aludir que a grande diversificação das atividades econômicas desenvolvidas na região de São João del-Rei, já nos anos de 1750, foi um dos fatores que possibilitou que os homens mais abastados preservassem seus patrimônios em um momento de crise da mineração e reorganização da economia da capitania de Minas Gerais. O que por sua vez indica que já nos primórdios da mineração atividades como a agropecuária, o comércio e a usura já compunham o leque mais amplo das atividades econômicas desempenhada pelas elites econômicas locais, indicando até mesmo certa independência dessas atividades frente às atividades mineradoras ${ }^{19}$, ou pelo menos uma conjugação desta com as demais atividades.

Em relação à mineração, como já explicitado, o fato de terem sido encontrados poucos inventários em que a atividade principal desempenhada pelo inventariado fosse a mineração deve ser relativizado. A maior parte dos inventários analisados é das décadas de 1780 e 1790 , portanto refletem um momento de decadência da exploração aurífera e fortalecimento das atividades agropastoris. Em alguns dos inventários pesquisados, mesmo naqueles enquadrados como agropastoris, há a presença de lavras, porém aparecem com um valor menor do que bens de raiz como fazendas, o que também pode ser reflexo da exaustão dos veios auríferos ali presentes.

Já quando se busca refletir o papel do comércio e dos grandes negociantes na economia da comarca do Rio das Mortes, o que tudo indica é que no decorrer da segunda metade dos setecentos a praça comercial sanjoanense não demonstrava a mesma pujança como aquela do século XIX estudada por Afonso de Alencastro Graça Filho (2002). O que, por sua vez, não indica que as práticas prestamistas e mercantis não estivessem presentes na composição das fortunas, mas sim que essas práticas ainda não eram suficientemente capazes de garantir autonomia frente às outras atividades econômicas, como as atividades agrárias.

A partir disso, é possível dizer que, se por um lado é inegável que as atividades de mineração tiveram uma importância fundamental para o enriquecimento dos homens bons de

\footnotetext{
${ }^{18}$ Arquivo Histórico de São João del-Rei/IPHAN - Inventários post-mortem - ano 1796, caixa 588.

${ }^{19}$ Sobre diversificação econômica ver GUIMARÃES, C.; REIS, F. (2007) e GUIMARÃES, C.; REIS, L. (1986).
} 
Minas, por outro, o comércio, a usura e as atividades ligadas à agropecuária, também compuseram o leque mais amplo de atuação econômica dessa elite já nos primórdios das atividades mineradoras desenvolvidas nas Minas (ALMEIDA, 2005) e estiveram presentes de forma significativa entre os anos de 1750 e 1800.

\section{REFERÊNCIAS BIBLIOGRÁFICAS}

ALMEIDA, C. Ricos e Pobres em Minas Gerais: produção e hierarquização social no mundo colonial, 1750-1822. Belo Horizonte: Argvmentvm, 2010.

. Homens ricos, homens bons: produção e hierarquização social em Minas colonial. Niterói: UFF, 2001 (Tese de Doutorado).

BERGAD, L. Escravidão e História Econômica: demografia de Minas Gerais, 1720-1888. Bauru: EDUSC, 2004.

BICALHO, M. "Elites coloniais: a nobreza da terra e o governo das conquistas. História e historiografia" In: MONTEIRO, N.; CARDIM, P.; CUNHA, M. (orgs.). Optima Pars: Elites ibero-americanas do Antigo Regime. Lisboa: ICS, 2005, pp. 73-97.

CANO, Wilson. Economia do ouro em Minas Gerais (século XVIII). Contexto. n .3, São Paulo, 1977, pp. 91-109.

CUNHA, A. Minas Gerais, da capitania à província: elites políticas e a administração da fazenda em um espaço em transformação. Tese de Doutorado. Niterói, Universidade Federal Fluminense, 2007.

FARIA, S. A Colônia: Paraíso ou Purgatório? In: A Colônia em Movimento: Fortuna e Família no Cotidiano Colonial. Rio de Janeiro: Nova Fronteira, 1998, pp. 223-288.

FRAGOSO, J. "Elites econômicas"em finais do século XVIII: mercado e política no centrosul da América lusa. Notas de uma pesquisa" In: JANCSÓ, István (org.). Independência: história e historiografia. São Paulo: Fapesp/Hucitec, 2005, pp. 849-880.

. Homens de grossa aventura: acumulação e hierarquia na praça mercantil do Rio de Janeiro, 1790-1830. Rio de Janeiro: Civilização Brasileira, 1998.

FURTADO, C. Formação econômica do Brasil. São Paulo: Ed. Nacional, 1977.

GRAÇA FILHO, A. A Princesa do Oeste e o Mito da Decadência de Minas Gerais: São João del-Rei (1831-1888). São Paulo: Annablume, 2002.

. A praça mercantil e a cidade de São João del-Rei no Oitocentos. In: PIRES, M., ANDRADE, F. \& BOHRER, A. Poderes e Lugares de Minas Gerais: um quadro urbano no interior brasileiro, séculos XVIII - XX. São Paulo: Scortecci; Ouro Preto: Editora UFOP, 2013, pp. 41-61. 
GUIMARÃES, C.; REIS, F. Agricultura e Mineração no século XVIII. In: História de Minas Gerais: As Minas Setecentistas 1. Belo Horizonte: Autêntica; Companhia do tempo, 2007, pp. 321-335.

; REIS, L. Agricultura e Escravidão em Minas Gerais. Revista do Departamento de História. Belo Horizonte, n. 2, 1986, pp. 7-36.

LOPES, Q. A dinâmica do mercado de propriedades rurais nas Minas Gerais setecentista: agricultura e mineração no termo de Mariana, comarca de Vila Rica, 1711-1780. Disponível em: http://www3.eeg.uminho.pt/aphes33/Comunica\%E7\%F5es/Lopes.pdf. Acessado em jul. 2014.

MALAQUIAS, C. População, Fronteira e Ruralização em São José do Rio das Mortes na passagem do século XVIII para o XIX. 2010. Disponível em: http://www.ilb.ufop.br/IIIsimposio/17.pdf. Acesso em jul. 2014.

MATHIAS, C. As múltiplas faces da escravidão. Rio de Janeiro: Mauad X/Faperj, 2012.

MATTOSO, K. Bahia, século XIX. Uma província no Império. Rio de Janeiro: Ed. Nova Fronteira, 1992.

MAXWELL, K. Confrontação. In: A Devassa da Devassa. A Inconfidência Mineira: Brasil e Portugal, 1750-1808. 6a Ed. São Paulo: Paz e Terra, 2005.

MELLO E SOUZA, Laura. Os desclassificados do ouro: a pobreza mineira no século XVIII. Rio de Janeiro: Graal, 1982.

MENESES, J. Produção de alimentos e atividade econômica na Comarca do Serro Frio século XVIII. IX Seminário sobre a Economia Mineira. Diamantina, 2000.

A terra de quem lavra e semeia: alimento e cotidiano em Minas Colonial. In: VILLALTA, L. \& RESENDE, M. História de Minas Gerais: As Minas Setecentistas 1. Belo Horizonte: Autêntica; Companhia do Tempo, 2007, pp. 337-358.

PRADO JUNIOR, C. Povoamento. In: Formação do Brasil contemporâneo. 23 Ed. São Paulo: Editora Brasiliense, 1994.

SAINT-HILAIRE, Auguste de. Viagem pelas províncias do Rio de Janeiro e Minas Gerais. Companhia Editora Nacional, 1938a. Disponível em: http://www.brasiliana.com.br/brasiliana/colecao/obras/82/Viagem-pelas-provincias-do-Riode-Janeiro-e-Minas-Gerais-t-1. Acesso em: 18 de agosto de 2015.

SAINT-HILAIRE, Auguste de. Segunda Viagem do Rio de Janeiro a Minas Gerais e a São Paulo (1822). Companhia Editora Nacional, 1938b. Disponível em: http://www.brasiliana.com.br/brasiliana/colecao/obras/5/Segunda-viagem-do-Rio-de-Janeiroa-Minas-Gerais-e-a-Sao-Paulo-1822. Acesso em: 18 de agosto de 2015.

SANTOS, R. Para além do ouro: dinâmica econômica e produção rural em uma região central da Capitania de Minas. História: Debates e Tendências, v. 9, n. 1, jan/jun. 2010, p. 188-203. 
SILVA, F. M. Práticas comerciais e abastecimento alimentar em Vila Rica na primeira metade do século XVIII. In: VILLALTA, L. \& RESENDE, M. História de Minas Gerais: As Minas Setecentistas 1. Belo Horizonte: Autêntica; Companhia do Tempo, 2007, pp. 359-376.

SILVA, F. C. T. Conquista e colonização da América Portuguesa: O Brasil Colônia 1500/1750. In: Linhares, M. (org.) História Geral do Brasil. Rio de Janeiro: Campus, 1990.

SIMONSEN, R. História econômica do Brasil (1500-1820). São Paulo: Ed. Nacional; Brasília: INL, 1977.

TEIXEIRA DA SILVA, F. C. A modernização autoritária. In: LINHARES, M. Y. História Geral do Brasil. Rio de Janeiro: Campus, 1990, pp. 252-295.

ZEMELLA, Mafalda P. O abastecimento da Capitania das Minas Gerais no século XVIII. 2. ed. São Paulo: HUCITEC - Editora da Universidade de São Paulo, 1990.

\section{FONTES DOCUMENTAIS MANUSCRITAS}

Acervo do Arquivo Histórico de São João del Rei/Instituto do Patrimônio Histórico e Artístico Nacional (IPHAN).

- Inventários post-mortem de São João del-Rei (1750-1800).

ARTIGO ENVIADO EM: 25/08/2015

ACEITO PARA PUBLICAÇÃO EM: 28/10/2015 